\title{
ДОВЕРИЕ КАК СОЦИАЛЬНО-ПСИХОЛОГИЧЕСКИЙ ФЕНОМЕН
}

\author{
А.Ю. Канева, \\ Н.Е. Коренкова \\ Московский гуманитарный университет
}

\begin{abstract}
Аннотация: В отечественных и зарубежных исследованиях по проблеме феномена доверия выражено довольно много точек зрения, как о составляющих этого сочиально-психологического явления, так и о факторах, влияюших на степень проявления изучаемого феномена. В статье проводится анализ теоретических аспектов доверия и феноменов, связанных с этим понятием.
\end{abstract}

Ключевые слова: доверие, феномен доверия, вера, сочиально-психологическое явление

\section{TRUST AS A SOCIO-PSYCHOLOGICAL PFENOMENON}

\author{
A. Y. Kaneva, \\ N. E. Korenkova \\ Moscow state University for the Humanities
}

\begin{abstract}
Foreign research on the problem of the phenomenon of trust, quite a lot of points of view are expressed both about the components of this socio-psychological phenomenon and the factors that affect the degree of manifestation of the phenomenon under study. The article analyzes the theoretical aspects of trust and the phenomena associated with this concept.
\end{abstract}

Keywords: trust, the phenomenon of trust, faith, socio-psychological phenomenon

Многие современные проблемы отдельных людей, коллективов и даже стран связаны с недостатком доверия. Недоверие порождает подозрения, которые провоцируют тревогу и служат почвой для развития недоброжелательности и других негативных эмоциональных проявлений, которые оказывают деструктивное воздействие на отношения. Важность доверия в возникновении эффективных и благоприятных отношений определяет актуальность изучения этого феномена в психологической науке.

В классической психологии феномен доверия используется для определения способов связи человека с миром, создания традиций внутрисемейных отношений, поддержания позиции «я-субъект собственной жизни», предотвращения «отчужденной активности» в социальном пространстве. По мнению многих специалистов здоровый человек потенциально способен к самораскрытию и созданию отношений с окружающими, основанных на доверии.

Доверие изучается в различных областях психологической науки. В таблице. 1 нами систематизированы и обобщены различные подходы к пониманию феномена доверия в психологии.

По мнению психологов, доверие - это основное, устойчивое отношение человека к миру, к самому себе. Доверие очень важно для психологического здо- 


\section{Подходы к пониманию доверия в психологии}

\begin{tabular}{|l|l|l|}
\hline \multicolumn{1}{|c|}{ Отрасль психологии } & \multicolumn{1}{|c|}{ Доверие понимается } & \multicolumn{1}{|c|}{ Автор } \\
\hline Социальная & $\begin{array}{l}\text { Социально-психологическое явление, ко- } \\
\text { торое необходимо изучать на различных } \\
\text { уровнях }\end{array}$ & $\begin{array}{l}\text { Т.П. Скрипкина } \\
\text { (Скрипкина, 2000) }\end{array}$ \\
\hline Практическая & $\begin{array}{l}\text { Показатель и фактор эффективности про- } \\
\text { цесса консультирования и психотерапии. }\end{array}$ & $\begin{array}{l}\text { Р. Кочунас } \\
\text { (Кочунас, 2000) }\end{array}$ \\
\hline Гуманистическая & $\begin{array}{l}\text { Экзистенциальная категория, которая яв- } \\
\text { ляется показателем психического здоро- } \\
\text { вья. }\end{array}$ & $\begin{array}{l}\text { Коджерс } \\
\text { Роджерс, 1997) }\end{array}$ \\
\hline Педагогическая & $\begin{array}{l}\text { Характеристика отношений и фактор их } \\
\text { эффективного развития на разных уровнях } \\
\text { взаимодействия в системе образования. }\end{array}$ & $\begin{array}{l}\text { П. Каптерев } \\
\text { (Каптерев, 1982) }\end{array}$ \\
\hline Политическая & $\begin{array}{l}\text { Моральный капитал сообщества } \\
\text { Ф. Фукуяма } \\
\text { (Фукуяма, 2008) }\end{array}$ \\
\hline
\end{tabular}

ровья. Насколько человек может доверять, зависит от его успешного развития и поведения.

Доверие - это многоуровневое образование, состоящее из:

- наборов первичных установок, которые формируются на начальных этапах онтогенеза, обусловленных необходимостью обеспечения безопасности;

- совокупности установок вторичного характера, когда доверие направлено как на мир, так и на самого себя, то есть определяет градацию людей, готовых доверять сильно и не очень.

В предметных ситуациях набор этих установок начинает взаимодействовать между собой, в результате чего конкретный индивид формирует обновленную установку, которая будет актуальна для данной конкретной ситуации.

Таким образом, уже на стадии восприятия определяется значимость объектов мира, т.е. к ним присоединяются ценности и смыслы. Таким образом, человек как бы «выносит» часть себя в мир, а это значит, что он «расширяет» себя в нем.

Но для того, чтобы взаимодействовать с миром, есть необходимое условие, которое заключается в удовлетворении вашего уровня безопасности. Это означает, что объекты взаимодействия должны быть не только значимыми для индивида, но и представлять собой удовлетворение потребности в относительной безопасности, которая станет катализатором вызова доверия и людей.

Доверие - это свойство людей наделять как объекты окружающего мира и связанные с ними явления, так и свои собственные действия, других индивидов свойствами значимости в текущей ситуации в синтезе с их относительной безопасностью. Доверие можно определить, как условие такого взаимодействия 
между миром и человеком, которое является предвестником наиболее активного взаимодействия. Изначальное доверие возникает во внутреннем мире индивида, и тогда можно регулировать доверие человеческой деятельностью: в момент взаимодействия оно как бы «навязывается» в самом акте взаимодействия, и потому существует в человеке, и возникает как бы между человеком и объектом в момент взаимодействия.

В самой системе психологических понятий важно различать элементарные понятия и подчиненные понятия. В понятийном аппарате различных школ и направлений существует множество синонимов и понятий, связанных с доверием. В работах многих авторов исследуются взаимоотношения и различия доверия с такими близкими понятиями, как «доверчивость», «надежность», «вера», «уверенность».

Рассмотрим широкий диапазон синонимичных понятий феномена доверия (табл. 2).

\section{Таблица 2}

\section{Синонимичные понятия феномена доверия}

\begin{tabular}{|l|l|}
\hline Tермины & \multicolumn{1}{|c|}{ Характеристика понятия } \\
\hline Вера & $\begin{array}{l}\text { Это иррациональное убеждение, доверию чаще всего необходимы основа- } \\
\text { ния, доказательства, проверка, оно подвергается сомнению (Скрипкина 2000; } \\
\text { Синютин 2004). } \\
\text { Вера - принятие возможности за действительность, обратная сторона веры - } \\
\text { скептицизм (Ильин, 2013). } \\
\text { Значение понятия «веры» шире «доверия» (Антоненко, 2006). } \\
\text { Объект доверия более конкретен, чем объект веры; доверию, в отличие от } \\
\text { веры, необходимы доказательства (Ильин, 2013). }\end{array}$ \\
\hline Уверенность & $\begin{array}{l}\text { Уверенность - это результат взаимоподкрепляемых ожиданий, в отличие от } \\
\text { доверия (Селигмен, 2002). } \\
\text { Уверенность касается чаще взаимодействия человека с функциональными } \\
\text { системами, такими как политика, а доверие направлено больше на межлич- } \\
\text { ностное взаимодействие (Селигмен, 2002). } \\
\text { Значение понятия «уверенность» шире «веры» и «доверия» (Антоненко, } \\
\text { 2006). }\end{array}$ \\
\hline Надежда & $\begin{array}{l}\text { Надежда более пассивное и нерациональное чувство, доверие имеет боль- } \\
\text { шую направленность (Кокуев, 2003). }\end{array}$ \\
\hline
\end{tabular}

Как отмечает А.Б. Купрейченко, можно графически отобразить место доверия в системе наиболее близких к нему понятий: веры, расчета, контроля и уверенности (Купрейченко, 2008). Представленная на рисунке 1 модель не включает многие другие факторы социальной ситуации, влияющие на формирование доверия. По мнению большинства исследователей, для возникновения доверия необходимы следующие обязательные условия: 


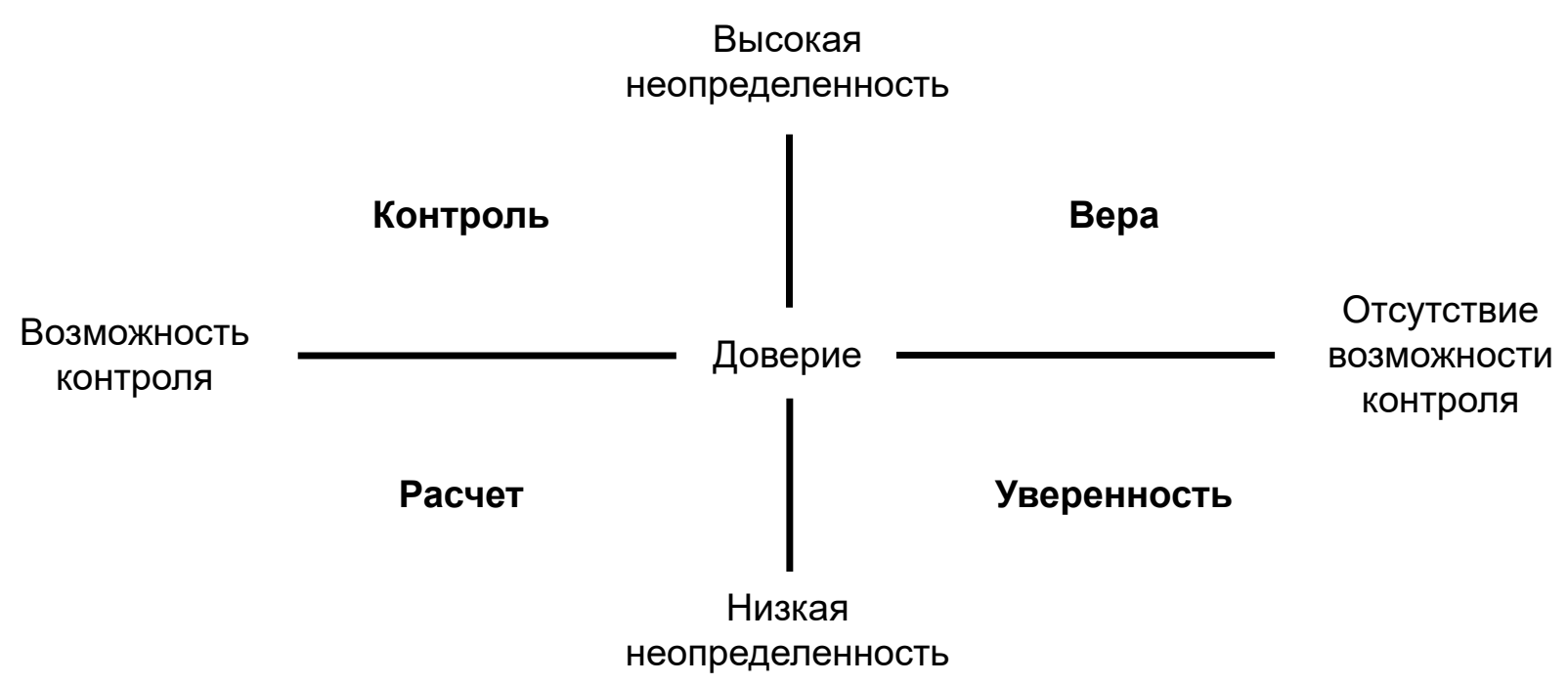

Рис. 1. Доверие в системе других понятий

1) наличие значимой ситуации, характеризующейся неопределенностью или связанной с риском;

2) оптимистическое ожидание субъекта относительно исхода события;

3) уязвимость субъекта и зависимость его от поведения других участников взаимодействия;

4) добровольность взаимодействия;

5) отсутствие контроля.

В контексте данного анализа важно, что большинство перечисленных условий доверия также являются и условиями возникновения недоверия, поскольку недоверие так же, как и доверие, возникает в ситуации неопределенности, уязвимости, отсутствия контроля.

Для описания поведенческой составляющей феномена доверия авторы опираются на философскую категорию «доброжелательность». Под этой категорией понимается готовность человека соблюдать все нормы морали, которые необходимы для поддержания взаимодействия с партнером. Он всегда должен быть готов проявить честность, доброжелательность и желание выложиться по максимуму при любых обстоятельствах, чтобы не был потерян только тот уровень доверия, который установился с конкретным человеком.

Можно выделить основные критерии, определяющие феномен доверия:

Знание (предсказуемость) - компонент, из которого складывается представление субъекта о том, насколько хорошо он знает партнера, и насколько он способен прогнозировать свое поведение в ситуации неопределенности.

Надежность - представление субъекта о том, способен ли другой человек помочь или поддержать в трудной ситуации. 
Единство (идентичность) - представление человека об общих целях, принципах и мировоззрении с другим человеком.

Симпатия и расчет - подразумевает симпатию и безусловный интерес к партнеру; расчет - желание проверить надежность партнера.

В целом, проведенный нами анализ теоретических аспектов доверия и феноменов, связанных с этим понятием, показал актуальность предмета данного исследования не только в психологии, но и в других научных дисциплинах, что подтверждает междисциплинарный статус понятия и соответствующую сложность его интерпретации.

Обнаружено наличие противоречивых подходов и расхождений в определении термина «доверие»: это и вера, и уверенность, и надежда. Доверие имеет широкий синонимический ряд, но оно также имеет отличительные черты. Это более узкое понятие, чем уверенность, более широкое, чем вера, и более направленное, чем надежда.

Как отмечает А.Б. Купрейченко, анализ происхождения доверия и недоверия вплотную подводит нас к рассмотрению функций, которые выполняют эти категории в жизни субъекта. Доверие и недоверие регулируют отношения с окружающим миром, воспроизводят социально-психологическое пространство человека, способствуют развитию субъекта и т.д.

В то же время и доверие, и недоверие имеют специфичные функции. Благодаря доверию субъект вступает во взаимодействие с миром, познает и преобразует его и себя. Именно доверие создает условия для обмена и взаимодействия субъекта с окружающим миром. Недоверие же способствует сохранению и обособлению субъекта и его социально-психологического пространства. В этом проявляется его защитная функция. Таким образом, еще одной характеристикой, способной разграничить доверие и недоверие, является «ориентация на обмен и взаимодействие - ориентация на сохранение и обособление».

Доверие вызывает исследовательский интерес специалистов в различных областях, так что мы можем наблюдать широкий спектр идей и взглядов на природу, функции доверия и объем результатов его изучения. В настоящее время существуют различные модели построения доверительных отношений, перспективных отношений и т.д. они влияют не только на понимание и восприятие феномена доверия, но и определяют вектор направления в изучении этого термина, что в конечном итоге не может не сказаться на интерпретации полученных результатов.

\section{СПИСОК ЛИТЕРАТУРЫ}

Антоненко И. В. (2006) Социально-психологическая концепция доверия. М.: Флинта; Наука. 480 с.

Ильин Е.П. (2013) Психология доверия. СПб.: Питер. 288 с.

Каптерев П.Ф. (1982) Избранные педагогические сочинения / под ред. 
А.М. Арсеньева; сост. П.А. Лебедев; Акад. пед. наук СССР. М.: Педагогика. 703 с. Кокуев А.А. (2003) Особенности доверия к себе и другим у несовершеннолетних преступников, отбывающих наказание в виде лишения свободы: автореф. дис. ... канд. психол. наук. Ростов-на-Дону. 21 с.

Кочюнас Р. (2000) Психотерапевтические группы, теория и практика. М.: Академический проект. $240 \mathrm{c}$.

Купрейченко А.Б. (2008) Психология доверия и недоверия. М.: Институт психологии РАН. 564 c.

Синютин М.В. (2004) Доверие и капиталистическая глобализация: российские метаморфозы // «Экономика и социология доверия» / под ред. Ю.В. Веселова, СПб.: СО им. М.М. Ковалевского. С. 135-150.

Скрипкина Т.П. (2000) Психология доверия: Учеб. пособие для студ. высш. пед. учебн. заведений. М. 264 с.

Роджерс К.Р. (1997) Теория личности. // Клиентоцентрированная терапия. М., $215 \mathrm{c}$.

Селигмен А. (2002) Проблема доверия. М.: Идея-Пресс, 256 с.

Фукуяма Ф. (2008) Доверие: социальные добродетели и путь к процветанию // пер. с англ. М.: АСТ. 730 с.

Канева Анна Юрьевна - магистрант кафедры общей, социальной психологии и истории психологии, Московского гуманитарного университета. Адрес: 111395., Россия, г. Москва, ул. Юности, д. 5. Тел.: 8(968) 970-86-58. Эл. адрес: anna.kaneva.19@mail.ru

Kaneva Anna Yurievna, master's student of the Department of General, Social Psychology and History of Psychology, Moscow University for the Humanities. Postal address: 5 Yunosti St., Moscow, Russian Federation 111395. Tel.: +7 (499) 374-67-20. E-mail: anna.kaneva.19@mail.ru

Коренкова Наталья Евгеньевна - кандидат психологических наук, доцент кафедры общей, социальной психологии и истории психологии, Московского гуманитарного университета. Адрес: 111395., Россия, г. Москва, ул. Юности. д. 5. Тел.: 8(909) 163-44-73. Эл. адрес: korenkova75@mail.ru

Korenkova Natalia Evgenievna, Candidate of Psychology, assistant professor of the Department of General, Social Psychology and History of Psychology, Moscow University for the Humanities. Postal address: 5 Yunosti St., Moscow, Russian Federation 111395. Tel.: +7 (499)374-67-20. E-mail: korenkova75@mail.ru

\section{Для цитирования:}

Канева А.Ю., Коренкова Н.Е. Доверие как социально-психологический феномен // Научные труды Московского гуманитарного университета. 2020. №5. C. 124-129. DOI: https:// www.doi.org/10.17805/trudy.2020.5.14 